\title{
REGULARITIES OF STABILITY FOR PRINTING FORMS OF OFFSET PRINTING WITH DAMPENING IN SHORT RUNS
}

\author{
Vasyl Skyba \\ Department of Reprography \\ Publishing and Printing Institute of the National Technical University of Ukraine \\ "Kyiv Polytechnic Institute" \\ 1/37 Ac. Yangel str., Kyiv, Ukraine, 03056 \\ v.skyba@kpi.ua \\ Kateryna Zolotukhina \\ Department of Reprography \\ Publishing and Printing Institute of the National Technical University of Ukraine \\ "Kyiv Polytechnic Institute" \\ 1/37 Ac. Yangel str., Kyiv, Ukraine, 03056 \\ k.zolotukhina@kpi.ua \\ Olena Velychko \\ Department of Reprography \\ Publishing and Printing Institute of the National Technical University of Ukraine \\ "Kyiv Polytechnic Institute" \\ 1/37 Ac. Yangel str., Kyiv, Ukraine, 03056 \\ o.velychko@kpi.ua
}

\begin{abstract}
The complex research for the changes in the properties of the printing plates' printing and gap elements influenced by the printing process short runs was conducted, that allowed to determine the change of printing and gap elements' surface microgeometry, also to determine the change of the oxide layer stability, and to explain the decrease of the ink receptivity coefficient. The mathematical regression equation model of the printing plates' elements' impact onto the imprints' optical density in offset printing was developed, that allows estimating and predicting properties of modern brand of printing plate. Work reveals some new facts about characteristics for printability such as influences of printing plate's elements parameters' on color characteristics of imprints. Dampening solution, printing plates application and printing settings as well as color features of the imprints are analyzed in the context of offset printing.

Keywords: plates; elements; fountain solution; offset; oxide film; ink transfer coefficient; imprints' optical density.

\section{Introduction}

In the printing industry the demands to the quality of printed products are constantly increasing, so the solution to ensure stable printing process parameters over the entire printrun is especially important. However, the printing runs of products are reduced and short-run difficulties arise stabilization process. The paper [1-7] summarizes recent studies of phenomena printed contact of offset printing. Today the market offers a sufficient number of plate materials having wide range of applications $[8,9]$. However, in the last decade, there are virtually no studies on the current range of printed forms surface interaction with a wide range of the developing and washout substances; also the impact of the printing contact parameters and consumables such as inks and dampening solutions on the printing elements properties and on the stability of gap elements is not researched as well. Research in this area reveals the nature and mechanism of these phenomena in printing contact, allowing to develop technological instructions for the rational use of specific modern material types according to the requirements of printed products, while stabilizing their production.
\end{abstract}

\section{Materials and Methods}

For the research the following offset printing monometallic plates were selected: photopolymer plates FUJIFILM Brillia LP-NV and thermal plates: IPAGSA Arte IP-21, Huaguang TP-II 
and XINGraphics FIT Melior Thermal. The chemical analysis of the non-printing gap elements surface on the offset printing plates was explored by X-ray spectral analysis method on X-ray spectral unit JOL Super Probe 733, temperature-programmed desorption mass spectrometry on mass spectrometer MX-7304. These methods are widely used in studies of different paper properties, microstructure, modified cellulosic fibers [6] and an assessment of changes in the exposure of thin layers [10]. The micro relief analysis and surface roughness of the printing plate was explored by electronic microscopy and strip chart recording. The simulation of printing contact was explored on laboratory offset proofing device LP-1; production tests were run on offset printing machine with dampening: RYOBI 522 PF, KBA Rapida 72, KBA Rapida 105, KBA Compacta C213 [11].

\section{Experimental procedures}

3. 1. Mathematical model of the printing plate's elements parameters' impact on the imprints' optical density value

The mathematical model of the printing plate's elements parameters' impact on the imprints' optical density value was developed. As control factors there were chosen: oxide layer concentration value on a surface of the non-printing element, printing and non-printing gap elements' surface roughness, ink transfer coefficient, and the imprints' optical density was selected as a dependent variable. The coefficients were calculated by the method of the least squares, the adequacy check was conducted by the Fisher criteria. The calculated equation has the following formulae:

$$
\begin{aligned}
& \mathrm{D}=0.02965 \cdot \mathrm{N}_{\text {of }} \cdot \mathrm{R}_{\mathrm{a}}^{\mathrm{PE}} \cdot \mathrm{R}_{\mathrm{a}}^{\mathrm{NPE}} \cdot \mathrm{K}_{\mathrm{i}}-0.02770 \cdot \mathrm{R}_{\mathrm{a}}^{\mathrm{PE}} \cdot \mathrm{R}_{\mathrm{a}}^{\mathrm{NPE}} \cdot \mathrm{K}_{\mathrm{i}}-0.17068 \cdot \mathrm{N}_{\text {of }} \cdot \mathrm{R}_{\mathrm{a}}^{\mathrm{NPE}} \cdot \mathrm{K}_{\mathrm{i}}+ \\
& +0,00435 \cdot \mathrm{N}_{\text {of }} \cdot \mathrm{R}_{\mathrm{a}}^{\mathrm{PE}} \cdot \mathrm{K}_{\mathrm{i}}-0,02565 \cdot \mathrm{N}_{\text {of }} \cdot \mathrm{R}_{\mathrm{a}}^{\mathrm{PE}} \cdot \mathrm{R}_{\mathrm{a}}^{\mathrm{NPE}}-0,06823 \cdot \mathrm{R}_{\mathrm{a}}^{\mathrm{NPE}} \cdot \mathrm{K}_{\mathrm{i}}+0,03120 \cdot \mathrm{R}_{\mathrm{a}}^{\mathrm{PE}} \cdot \mathrm{K}_{\mathrm{i}}+ \\
& +0,01485 \cdot \mathrm{R}_{\mathrm{a}}^{\mathrm{PE}} \cdot \mathrm{R}_{\mathrm{a}}^{\mathrm{NPE}}+0,03848 \cdot \mathrm{N}_{\text {of }} \cdot \mathrm{K}_{\mathrm{i}}+0,04818 \cdot \mathrm{N}_{\text {of }} \cdot \mathrm{R}_{\mathrm{a}}^{\mathrm{NPE}}-0,04855 \cdot \mathrm{N}_{\text {of }} \cdot \mathrm{R}_{\mathrm{a}}^{\mathrm{PE}}- \\
& -0,17078 \cdot \mathrm{K}_{\mathrm{i}}+0,11308 \cdot \mathrm{R}_{\mathrm{a}}^{\mathrm{NPE}}+0,07155 \cdot \mathrm{R}_{\mathrm{a}}^{\mathrm{PE}}+0,14188 \cdot \mathrm{N}_{\text {of }}+1,67848,
\end{aligned}
$$

where $\mathrm{N}_{\text {of }}$ - oxide layer concentration value on a surface of the non-printing element; $\mathrm{R}_{\mathrm{a}}^{\mathrm{PE}}$ - roughness of printing elements' surface for the parameter $\mathrm{Ra} ; \mathrm{R}_{\mathrm{a}}^{\mathrm{NPE}}$ - roughness of gap elements' surface for the parameter $\mathrm{Ra} ; \mathrm{K}_{\mathrm{i}}$ - ink transfer coefficient.

Therefore controlling such parameters as oxide layer concentration value on surface of a non-printing element, printing and non-printing gap elements' surface roughness, ink transfer coefficient makes possible to forecast the value of the optical density on the imprint in a certain period of printing plate exploitation and to determine its change during the printrun.

The proposed model allows estimating and predicting properties of any modern brand of printing plate being produced in the conditions of the modern manufacturing site using existing equipment and materials.

\section{2. Research of printing plates properties}

The analysis of scientific works showed concrete major role of non-printing gap elements of the offset printing plates in stabilizing text and illustrations reproduction regardless of material's nature.

Referring to the stated above, the model the printing form surface structure is characterized by a certain primary hyperfine oxide layer which forms the printing-technical properties of the gap elements, and provides the adhesive strength for fixing the printing elements $[1,8,11,12]$.

Porous structure of the surface gap element should also be considered as a system of open capillaries (narrow channels), which can transport water or fountain solution. While contacting with the fountain solution not only the surface of capillary hole but also its inner walls are wetted, creating a capillary pressure. As a result, becomes possible a situation when porous surface volume of gap element absorbs fountain solution and continues to hold it.

Thus, to stabilize the hydrophilic properties of the gap element it is necessary to form the thinnest layers with hydrophilic agents not only on the surface, but also in the oxide film porous structure depth. This process is based on the oriented adsorption of hydrophilic agent's molecules on the porous surface resulting in creating the hydrophilic mono- or poly-molecular thin layers. 
However, in the printing process under the printing contact factors influence (such as pressure, printing speed, ink, fountain solution, and paper impact), the original structure of the printing form elements surface suffers the changes directly affecting their properties.

The research of modern brand's printing plates' printing and gap elements surface layers showed a significant change in the morphology of the surface itself [11].

The change character of the printing and gap elements (Fig. 1, curves 1,2) researched by the author correlates with the imprint's quality parameter's changes and is determined by impression factors in the print contact; it reveals as plastic deformation and destruction of the printing form surface layers. When increasing the printrun, the local destruction of the gap element's oxide film happens under the impact of loads, while accumulating various crystallographic defects that intensify wear [12].

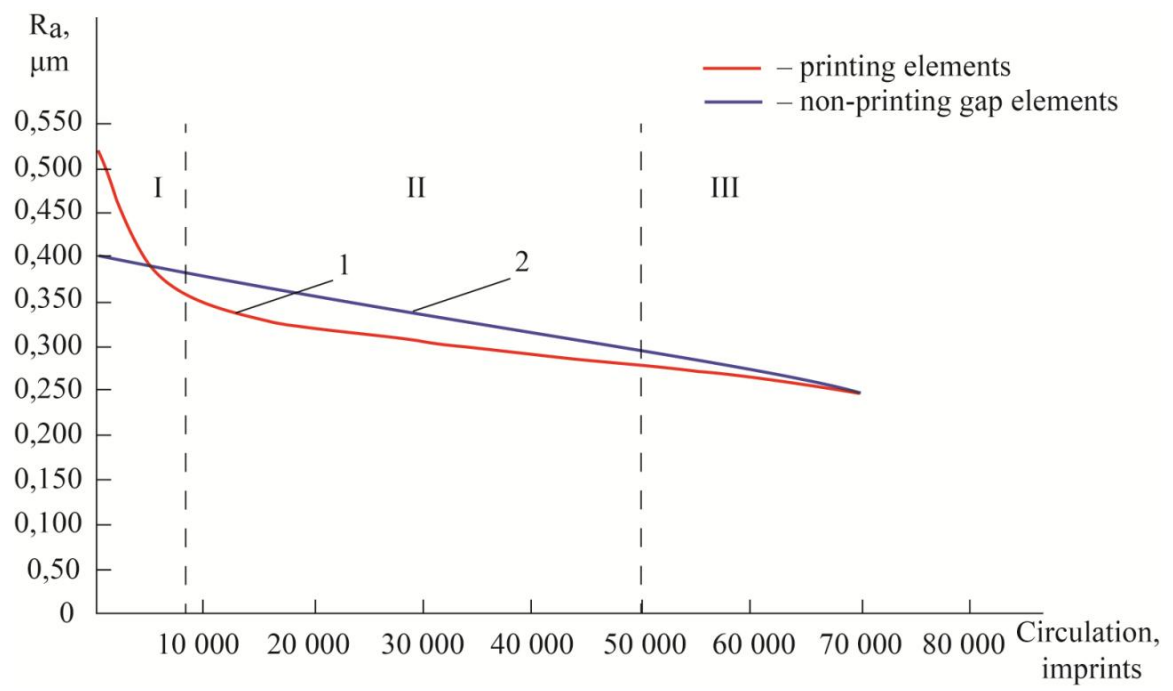

Fig. 1. Surface roughness of printing form (parameter $\mathrm{R}_{\mathrm{a}}$ ): 1 - printing elements; 2 - non-printing gap elements; process steps: I - burnishing; II - stabilization; III - further deterioration

The character of stability changes of the oxide film under the influence of the printing process was determined by X-ray analysis; this represents the reduction of mass fractions of chemical elements of its components and the subsequent loss of surface hydrophilic properties of non-printing gap elements (Fig. 2). The sharp decline in the mass fraction of silicon is typical during the printing of up to 10000 imprints, because of the active running-surface of printing plate: change the initial and the creation of a new working surface micro-geometry. As a result of that the microroughnesses of the thin layers are getting maximum deformation impact on the peaks, where, actually, a large number of hydrophilic compound's molecules and combinations are adsorbed. During printing, gradual reduction of mass fractions of oxygen and sodium occurs because of physical and chemical processes happening on the surface of non-printing gap element [11].

Adsorption of surface-active substances with a fountain solution on a surface and into micro-cracks of the oxide film during printing leads to the intensification of deformation and destruction of the oxide layer.

The temperature-programmed desorption mass spectrometry (Fig. 3) was used by the author to study the impact of printing process's tribochemical contact on the composition and structure change of a printing and gap elements of a printing plate before printing process (Fig. 3, a) and after printing process, 70.0 thousand imprints (Fig. 3, b); this confirms decreasing of the component's presence, which are forming a hydrophilic film, also resulting in gradual loss of non-printing surface's wetting.

Furthermore, the capillary structure destruction under impression impact leads to capillary pores of the oxide film replenishment decrease, which significantly lowers the ability to retain stored fountain solution on the surface of the non-printing gap elements. 


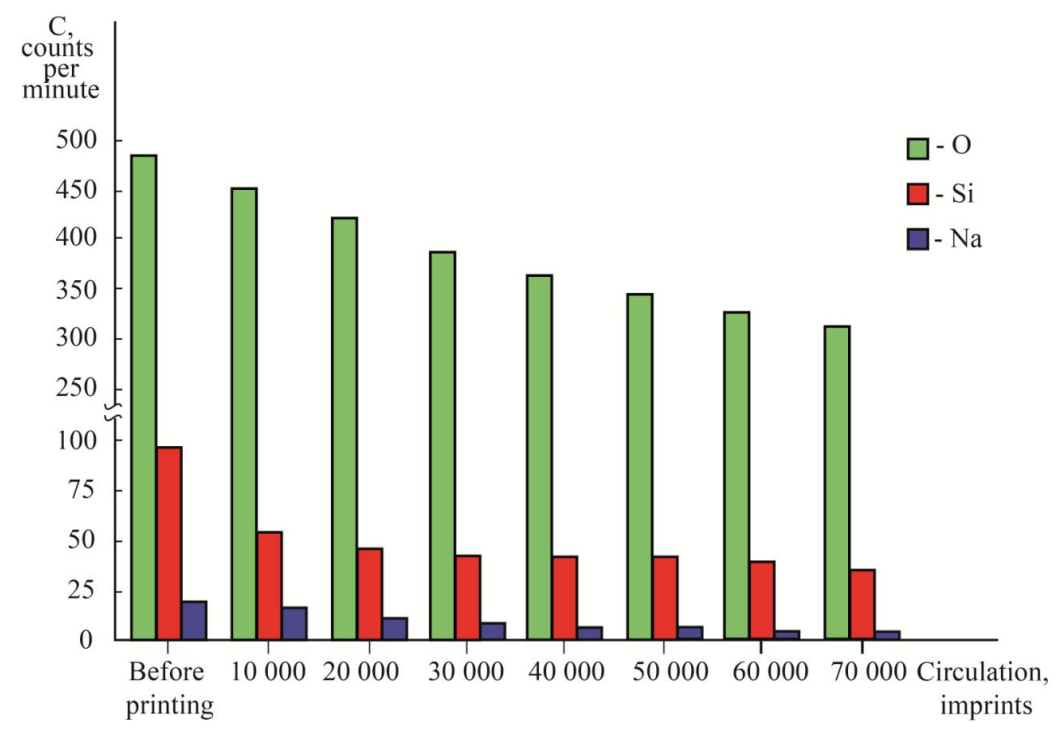

Fig. 2. Change of the oxide film stability on non-printing gap elements of printing plates during the printrun
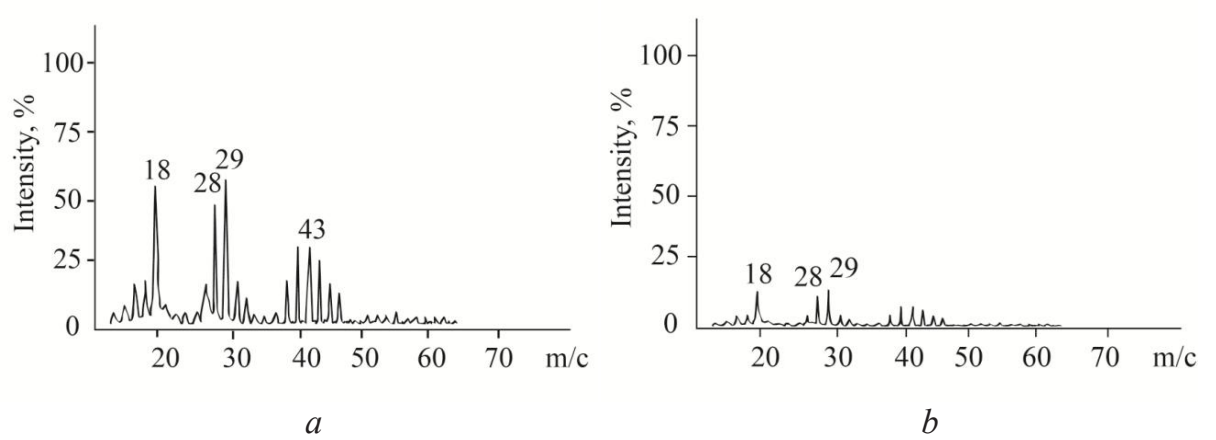

Fig. 3. Mass spectrum of non-printing gap element: $a$-before; $b$-after printing process; printrun - 70.0 thousand imprints. Molecular weight: 18 - Water $\left(\mathrm{H}_{2} \mathrm{O}\right) ; 28$ - nitrogen compounds $(\mathrm{N})$; 29 - silicium compounds $(\mathrm{SiH}) ; 43$ - silicium derivatives $\left(\mathrm{SiCH}_{3}\right)$

\section{Results and discussion}

The conducted research of the printing process impact on change of such important printingtechnical parameters as ink receptivity and ink transfer of printing plates (using a laboratory offset proofing device LP-1) showed that the ink is transferred on the surface of the printing elements in proportion to the amount required for complete saturation in the values set regarding the original thickness of the ink layer (Fig. 4). And as because the roughness is not large, the printing element's ink receptivity coefficient does not have high values. So, only one third of the original ink layer is transferred to the printing plate. There is a descending tendency from 23 to $14 \%$ of the ink receptivity coefficient for the printing plate having been in impression (Fig. 4), that corresponds with the changes of a surface roughness during the printing process because the printing plate saturation occurs with thinner inks layers (Fig. 4).

The analysis of ink transfer coefficient from the printing plate to the paper also showed the general pattern for the same printing contact conditions which are typical for offset paper (Fig. 5, curve 2). However, ink transfer for coated paper has got more extreme characteristic (Fig. 5, curve 1).

The substantial natural residual layer of fountain solution, which is not absorbed by paper was also found while comparing new printing plates with worn (the laboratory proofing device LP-1 was used). For new printing plate gap elements and 70000 imprints old printing plate gap elements the complete absorption period of fountain solution goes on for about three imprints. This layer varies between $1,08-0,25 \mu \mathrm{m}$ for the non-printing gap elements of a new printing plate, and 
within 2,23-0,02 $\mu \mathrm{m}$ for the non-printing gap elements that have already run 70.0 thousand imprints (Fig. 6). This matches the described above phenomena of porosity changes, micro-geometry and composition changes of gap elements under the impact of impression.

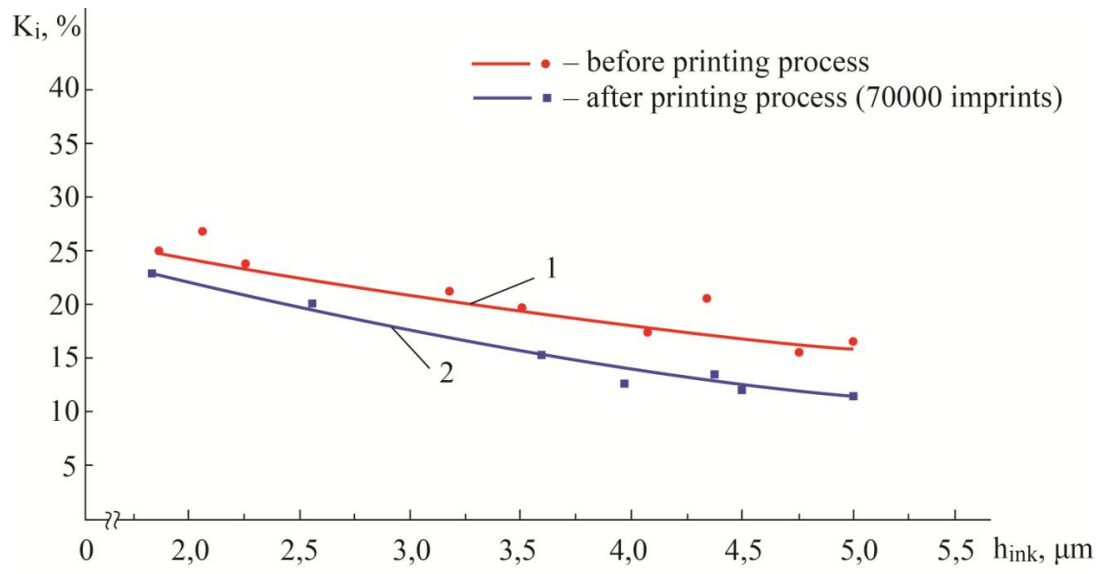

Fig. 4. The ink receptivity coefficient of printing plates with the printing conditions of $1.1 \mathrm{MPa}$ impression; speed $-2.5 \mathrm{~m} / \mathrm{s}$ : 1 - before printing process; 2 - after printing process (70000 imprints)

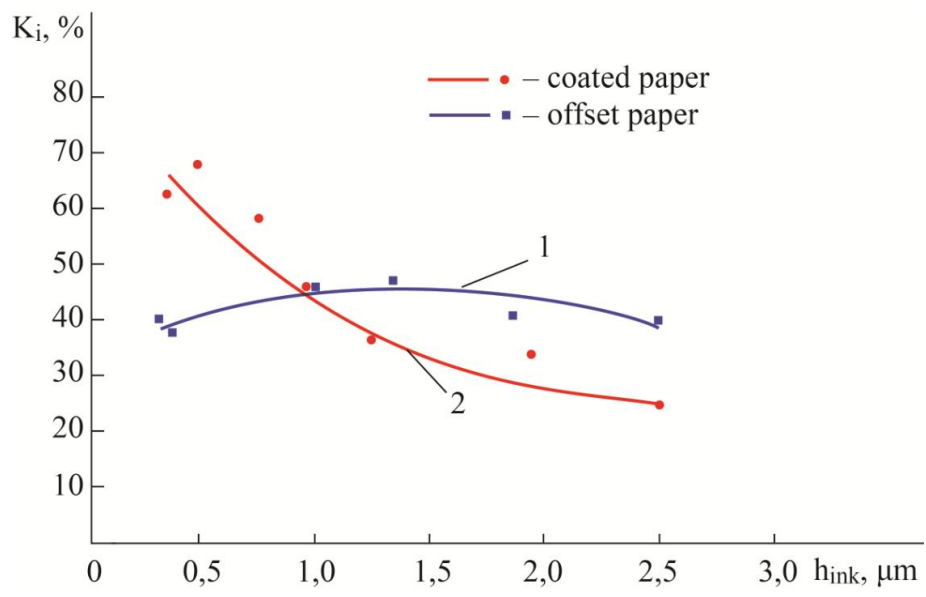

Fig. 5. The coefficient of ink transfer from printing plates on paper depending on the printing contact, with the printing conditions of $1.1 \mathrm{MPa}$ impression; speed - $2.5 \mathrm{~m} / \mathrm{s}: 1$ - coated paper; 2 - offset paper

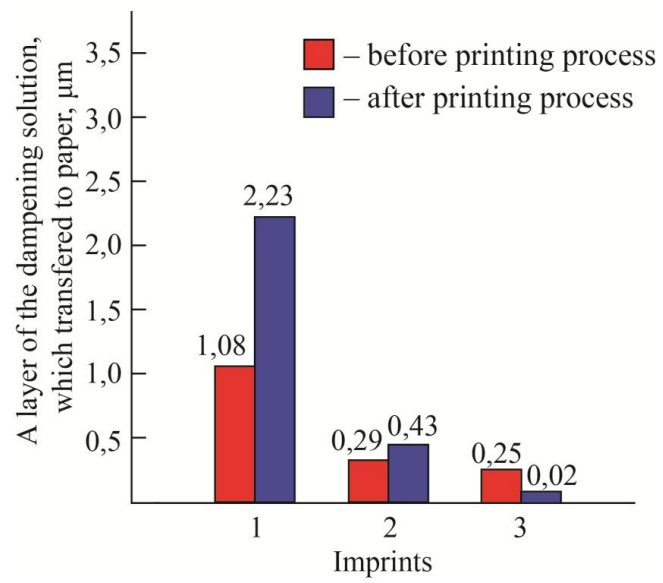

Fig. 6. The transfer of the dampening solution from printing plate to offset paper 
Therefore, hydrophilic substances adsorbed on a surface and in-depth structure of non-printing gap elements during their exploitation are responsive to physical and chemical and physical-mechanical impact of impression. They may provide their functionality only for a certain printrun until they are completely worked out, that results in gradual wetting deterioration of the printing plate and can cause a negative greasing phenomena of non-printing gap elements.

\section{Conclusions}

1. The complex research for the changes in the properties of the printing plates' printing and gap elements influenced by the printing process was conducted, that allowed to determine the change of printing and gap elements' surface microgeometry, also to determine the change of the oxide layer stability as a result of destruction and wear of its porous structure, and to explain the decrease of the ink receptivity coefficient.

2. The mathematical regression equation model of the printing plates' elements' impact onto the imprints' optical density in offset printing was developed and calculated, that allows estimating and predicting properties of any modern brand of printing plate being produced in the conditions of the modern manufacturing site using existing equipment and materials.

3. It is advisable to continue investigating the structure and properties of the non-printing elements, depending on the components of the dampening solution and its changes under the influence of factors printed contact.

\section{References}

[1] Poljanskij, N., Kartasheva, O.\& Nadirova, E. (2010). Platemaking technology. Moscow: MGUP, 366.

[2] Kuznetsov, Y. V. (2016). Basics illustrative printing technology. St. Petersburg: Russian literature, 440 .

[3] Zorenko, Y. (2015). Halftone Imprint's parameters in modern methods of color reproduction. Technology and Technique of Typography, 1 (47), 24-29. Available at: http://ttdruk.vpi.kpi.ua/article/ view/43270/39737

[4] Khohlova, R. A., Velychko, O. M. (2014). Finishing printed products of varnishing. PPC Kyiv University, 183.

[5] Nechiporenko, N. A., Berdovschikova, A. V., Bozojan, M.A. (2013). The choice of the concentrate and to determine the optimal formulation of fountain solution for sheetfed offset printing. Proceedings of the higher educational institutions. Problems of printing and publishing, 6, 30-42.

[6] Kushlyk, B. (2011). An analysis of ink-water emulsion behavior in the process of offset printing with moistening of printing forms. Technology and Technique of Typography, 4, 34-45. Available at: http:// ttdruk.vpi.kpi.ua/article/view/33485

[7] Blagodir, O., Zolotukhina, K., Kushlyk, B., Velychko, O. (2016). Regularities of ink-water balance stability in offset printing. EUREKA: Physics and Engineering, 3, 31-37. Available at: http://eu-jr.eu/ engineering/article/view/78/77

[8] Trautseddel, R., Volf, K. (2003). Surface effects in offset printing forms. Technology and Technique of Typography, 1, 42-45. Available at: http://druk.kpi.ua/files/publications/2003-1-8.pdf

[9] Litunov, S. N., Yjusha, V. L., Toshakova, Y. D. (2015). Determination structuring zones thixotropic liquid when driving. Proceedings of the higher educational institutions. Problems of printing and publishing, 5, 29-36. Available at: http://mgup.ru/article/1840

[10] Nechyporchuk, O., Pignon, F., Belgacem, M. N. (2015). Morphological properties of nanofibrillated cellulose produced using wet grinding as an ultimate fibrillation process. Journal of Materials Science, 50 (2), 531-541. doi: 10.1007/s10853-014-8609-1

[11] Skyba, V., Koval, O., Velychko, O. (2010). Chemical analysis of surface of spaces of forms of offset printing by the method of x-ray microanalysis. Technology and Technique of Typography, 4, 198-205. Available at: http://ttdruk.vpi.kpi.ua/article/view/55783/51948

[12] Skyba, V. (2015). Technological foundations of stability the lottery printing plates. Kyiv: PPC Kyiv University, 148. 